\title{
A new result on the existence of periodic solutions for Liénard equations with a singularity of repulsive type
}

\section{Shiping Lu*}

\section{"Correspondence: \\ ftxlsp@outlook.com \\ College of Math \& Statistics, Nanjing \\ University of Information Science and Technology, Nanjing, 210044 China}

\begin{abstract}
In this paper, the problem of the existence of a periodic solution is studied for the second order differential equation with a singularity of repulsive type

$$
x^{\prime \prime}(t)+f(x(t)) x^{\prime}(t)-g(x(t))+\varphi(t) x(t)=h(t),
$$

where $g(x)$ is singular at $x=0, \varphi$ and $h$ are $T$-periodic functions. By using the continuation theorem of Manásevich and Mawhin, a new result on the existence of positive periodic solution is obtained. It is interesting that the sign of the function $\varphi(t)$ is allowed to change for $t \in[0, T]$.
\end{abstract}

MSC: $34 \mathrm{C} 25 ; 34 \mathrm{~B} 16 ; 34 \mathrm{~B} 18$

Keywords: Liénard equation; topological degree; singularity; periodic solution

\section{Introduction}

The aim of this paper is to search for positive $T$-periodic solutions for a second order differential equation with a singularity in the following form:

$$
x^{\prime \prime}(t)+f(x(t)) x^{\prime}(t)-g(x(t))+\varphi(t) x(t)=h(t)
$$

where $f:[0, \infty) \rightarrow R$ is an arbitrary continuous function, $g \in C((0,+\infty),(0,+\infty))$, and $g(x)$ is singular of repulsive type at $x=0$, i.e., $g(x) \rightarrow+\infty$ as $x \rightarrow 0^{+}, \varphi, h: R \rightarrow R$ are $T$ periodic functions with $h \in L^{2}([0, T], R)$ and $\varphi \in C([0, T], R)$, and the sign of the function $\varphi$ is allowed to change for $t \in[0, T]$.

The study of the problem of periodic solutions to scalar equations with a singularity began with work of Forbat and Huaux [1,2], where the singular term in the equations models the restoring force caused by a compressed perfect gas (see [3-6] and the references therein). In the past years, many works used the methods, such as the approaches of critical point theory [7-12], the techniques of some fixed point theorems [13-15], and the approaches of topological degree theory, in particular, of some continuation theorems of Mawhin (see [6, 16-22]), to study the existence of positive periodic solutions for some second order ordinary differential equations with singularities. For example, in [15], by using a fixed point theorem in cones, the existence of positive periodic solutions to equation

(c) The Author(s) 2017. This article is distributed under the terms of the Creative Commons Attribution 4.0 International License (http://creativecommons.org/licenses/by/4.0/), which permits unrestricted use, distribution, and reproduction in any medium, provided you give appropriate credit to the original author(s) and the source, provide a link to the Creative Commons license, and indicate if changes were made. 
(1.1) was investigated for the conservative case, i.e., $f(x) \equiv 0$. But the function $\varphi(t)$ is required to be $\varphi(t) \geq 0$ for all $t \in[0, T]$. The method of topological degree theory, together with the technique of upper and lower solutions, was first used by Lazer and Solimini in the pioneering paper [18] for considering the problem of a periodic solution to a second order differential equations with singularities. Jebelean and Mawhin in [6] considered the problem of a $p$-Laplacian Liénard equation of the form

$$
\left(\left|x^{\prime}\right|^{p-2} x^{\prime}\right)^{\prime}+f(x) x^{\prime}+g(x)=h(t)
$$

and

$$
\left(\left|x^{\prime}\right|^{p-2} x^{\prime}\right)^{\prime}+f(x) x^{\prime}-g(x)=h(t)
$$

where $p>1$ is a constant, $f:[0,+\infty) \rightarrow R$ is an arbitrary continuous function, $h: R \rightarrow R$ is a $T$-periodic function with $h \in L^{\infty}([0, T], R), g:(0,+\infty) \rightarrow(0,+\infty)$ is continuous, $g(x) \rightarrow$ $+\infty$ as $x \rightarrow 0^{+}$. They extended the results of Lazer and Solimini in [16] to equation (1.2) and equation (1.3). For equation (1.3), the crucial condition is that the function $g(x)$ is bounded, which means that equation (1.3) is not singular at $x=+\infty$.

By using a continuation theorem of Mawhin, Zhang in [18] studied the problem of periodic solutions of the Liénard equation with a singularity of repulsive type,

$$
x^{\prime \prime}+f(x) x^{\prime}+g(t, x)=0,
$$

where $f: R \rightarrow R$ is continuous, $g: R \times(0,+\infty) \rightarrow R$ is an $L^{2}$-Carathéodory function with $T$-periodic in the first argument, and it is singular at $x=0$, i.e., $g(t, x)$ is unbounded as $x \rightarrow 0^{+}$. Different from the equation studied in $[6,16]$, which is only singular at $x=0$, equation (1.4) is provided with both singularities at $x=+\infty$ and at $x=0$. In [19], Wang further studied the existence of positive periodic solutions for a delay Liénard equation with a singularity of repulsive type

$$
x^{\prime \prime}+f(x) x^{\prime}+g(t, x(t-\tau))=0 .
$$

In $[18,19]$, the following balance condition between the singular force at the origin and at infinity is needed.

$\left(\mathrm{h}_{1}\right)$ There exist constants $0<D_{1}<D_{2}$ such that if $x$ is a positive continuous $T$-periodic function satisfying

$$
\int_{0}^{T} g(t, x(t)) d t=0
$$

then

$$
D_{1} \leq x(\tau) \leq D_{2}, \quad \text { for some } \tau \in[0, T]
$$

From the proof of $[18,19]$, we see that the balance condition $\left(h_{1}\right)$ is crucial for estimating $a$ priori bounds of periodic solutions. Now, the question is how to investigate the existence 
of positive periodic solutions for the equations like equation (1.4) or equation (1.5) without the balance condition $\left(\mathrm{h}_{1}\right)$.

Motivated by this, in this paper, we study the existence of positive $T$-periodic solutions for equation (1.1) under the condition that the sign of the function $\varphi$ is allowed to change for $t \in[0, T]$. For this case, the balance condition $\left(\mathrm{h}_{1}\right)$ may not be satisfied. By using the continuation theorem of Manásevich and Mawhin, a new result on the existence of positive periodic solutions is obtained.

\section{Preliminary lemmas}

Throughout this paper, let $C_{T}=\{x \in C(R, R): x(t+T)=x(t)$ for all $t \in R\}$ with the norm defined by $|x|_{\infty}=\max _{t \in[0, T]}|x(t)|$. For any $T$-periodic solution $y(t)$ with $y \in L^{1}([0, T], R), y_{+}(t)$ and $y_{-}(t)$ denote $\max \{y(t), 0\}$ and $-\min \{y(t), 0\}$, respectively, and $\bar{y}=\frac{1}{T} \int_{0}^{T} y(s) d s$. Clearly, $y(t)=y_{+}(t)-y_{-}(t)$ for all $t \in R$, and $\bar{y}=\overline{y_{+}}-\overline{y_{-}}$.

The following lemma is a consequence of Theorem 3.1 in [23].

Lemma 1 Assume that there exist positive constants $M_{0}, M_{1}$, and $M_{2}$ with $0<M_{0}<M_{1}$, such that the following conditions hold.

1. For each $\lambda \in(0,1]$, each possible positive $T$-periodic solution $x$ to the equation

$$
u^{\prime \prime}+\lambda f(u) u^{\prime}-\lambda g(u)+\lambda \varphi(t) u=\lambda h(t)
$$

satisfies the inequalities $M_{0}<x(t)<M_{1}$ and $\left|x^{\prime}(t)\right|<M_{2}$ for all $t \in[0, T]$.

2. Each possible solution $c$ to the equation

$$
g(c)-c \bar{\varphi}+\bar{h}=0
$$

satisfies the inequality $M_{0}<c<M_{1}$.

3. We have

$$
\left(g\left(M_{0}\right)-\bar{\varphi} M_{0}+\bar{h}\right)\left(g\left(M_{1}\right)-\bar{\varphi} M_{1}+\bar{h}\right)<0 .
$$

Then equation (1.1) has at least one T-periodic solution $u$ such that $M_{0}<u(t)<M_{1}$ for all $t \in[0, T]$.

Lemma 2 ([19]) Let $x$ be a continuous T-periodic continuously differential function. Then, for any $\tau \in(0, T]$,

$$
\left(\int_{0}^{T}|x(s)|^{2} d s\right)^{1 / 2} \leq \frac{T}{\pi}\left(\int_{0}^{T}\left|x^{\prime}(s)\right|^{2} d s\right)^{1 / 2}+\sqrt{T}|x(\tau)| .
$$

In order to study the existence of positive periodic solutions to equation (1.1), we list the following assumptions.

$\left[\mathrm{H}_{1}\right]$ The function $\varphi(t)$ satisfies the following conditions:

$$
\int_{0}^{T} \varphi_{+}(s) d s>0, \quad \sigma:=\frac{\int_{0}^{T} \varphi_{-}(s) d s}{\int_{0}^{T} \varphi_{+}(s) d s} \in[0,1)
$$


and

$$
\sigma_{1}:=\frac{T}{\pi}\left|\varphi_{+}\right|_{\infty}^{1 / 2}+\frac{T^{\frac{1}{2}}\left(\int_{0}^{T} \varphi_{-}(s)^{2} d s\right)^{\frac{1}{2}}}{\int_{0}^{T} \varphi_{+}(s) d s} \in(0,1) ;
$$

$\left[\mathrm{H}_{2}\right]$ there are constants $A>0$ and $M>0$ such that $g(x) \in(0, A)$ for all $x>M$;

$\left[\mathrm{H}_{3}\right] \int_{0}^{1} g(s) d s=+\infty$.

Remark 1 If assumptions $\left[\mathrm{H}_{1}\right]-\left[\mathrm{H}_{2}\right]$ hold, then there are constants $D_{1}$ and $D_{2}$ with $0<$ $D_{1}<D_{2}$ such that

$$
g(x)-\bar{\varphi} x+\bar{h}>0 \quad \text { for all } x \in\left(0, D_{1}\right)
$$

and

$$
g(x)-\bar{\varphi} x+\bar{h}<0 \quad \text { for all } x \in\left(D_{2}, \infty\right) .
$$

Furthermore, assumption $\sigma_{1} \in(0,1)$ in $\left[\mathrm{H}_{1}\right]$ is different from the corresponding condition $\int_{0}^{T} \varphi_{+}(s) d s<\frac{4}{T}$ in $[20]$.

Now, we suppose that assumptions $\left[\mathrm{H}_{1}\right]$ and $\left[\mathrm{H}_{2}\right]$ hold, and we embed equation (1.1) into the following equation family with a parameter $\lambda \in(0,1]$ :

$$
x^{\prime \prime}+\lambda f(x) x^{\prime}-\lambda g(x)+\lambda \varphi(t) x=\lambda h(t), \quad \lambda \in(0,1] .
$$

Let

$$
\Omega=\left\{x \in C_{T}: x^{\prime \prime}+\lambda f(x) x^{\prime}-\lambda g(x)+\lambda \varphi(t) x=\lambda h(t), \lambda \in(0,1] ; x(t)>0, \forall t \in[0, T]\right\},
$$

and

$$
M_{0}=\frac{\left(\int_{0}^{T} \varphi_{-}(s)^{2} d s\right)^{\frac{1}{2}}}{\int_{0}^{T} \varphi_{+}(s) d s} A_{0}^{2}+\frac{A+|\bar{h}|}{\overline{\varphi_{+}}}+\left|\varphi_{+}\right|_{\infty} A_{0}^{2} T^{\frac{1}{2}}+A_{0} T^{\frac{1}{2}}\left(\int_{0}\left|h_{-}(t)\right|^{2} d t\right)^{\frac{1}{4}},
$$

where

$$
A_{0}=\frac{T}{\pi\left(1-\sigma_{1}\right)}\left(\int_{0}^{T}\left|h_{-}(t)\right|^{2} d t\right)^{\frac{1}{4}}+\left(\frac{(A+|\bar{h}|) T^{\frac{1}{2}}}{\left(1-\sigma_{1}\right) \overline{\varphi_{+}}}\right)^{\frac{1}{2}},
$$

$A>0$ is a constant determined by assumption $\left[\mathrm{H}_{2}\right]$. Clearly, $M_{0}$ and $A_{0}$ are all independent of $(\lambda, x) \in(0,1] \times \Omega$. Let $M>0$ be determined by assumption $\left[\mathrm{H}_{2}\right]$, then there is a positive integer $k_{0}$ such that

$$
k_{0} M \geq M_{0} .
$$

Lemma 3 Assume that assumptions $\left[\mathrm{H}_{1}\right]-\left[\mathrm{H}_{2}\right]$ hold, then there is an integer $k^{*}>k_{0}$ such that, for each function $u \in \Omega$, there is a point $t_{0} \in[0, T]$ satisfying

$$
u\left(t_{0}\right) \leq k^{*} M .
$$


Proof If the conclusion does not hold, then, for each $k>k_{0}$, there is a function $u_{k} \in \Omega$ satisfying

$$
u_{k}(t)>k M \quad \text { for all } t \in[0, T]
$$

From the definition of $\Omega$, we see

$$
u_{k}^{\prime \prime}+\lambda f\left(u_{k}\right) u_{k}^{\prime}-\lambda g\left(u_{k}\right)+\lambda \varphi(t) u_{k}=\lambda h(t), \quad \lambda \in(0,1],
$$

and by using assumption $\left[\mathrm{H}_{2}\right]$,

$$
0<g\left(u_{k}(t)\right)<A, \quad \text { for all } t \in[0, T] .
$$

By integrating equation (2.5) over the interval $[0, T]$, we have

$$
\int_{0}^{T} \varphi(t) u_{k}(t) d t=\int_{0}^{T} g\left(u_{k}(t)\right) d t+\int_{0}^{T} h(t) d t
$$

i.e.,

$$
\int_{0}^{T} \varphi_{+}(t) u_{k}(t) d t=\int_{0}^{T} \varphi_{-}(t) u_{k}(t) d t+\int_{0}^{T} g\left(u_{k}(t)\right) d t+\int_{0}^{T} h(t) d t .
$$

Since $\varphi_{+}(t) \geq 0$ and $\varphi_{-}(t) \geq 0$ for all $t \in[0, T]$, it follows from the integral mean value theorem that there is a point $\xi \in[0, T]$ such that

$$
\begin{aligned}
u_{k}(\xi) \int_{0}^{T} \varphi_{+}(t) d t & =\int_{0}^{T} \varphi_{-}(s) u_{k}(s) d s+\int_{0}^{T} g\left(u_{k}(t)\right) d t+T \bar{h} \\
& \leq\left(\int_{0}^{T} \varphi_{-}(s)^{2} d s\right)^{\frac{1}{2}}\left(\int_{0}^{T}\left|u_{k}(s)\right|^{2} d s\right)^{\frac{1}{2}}+\int_{0}^{T} g\left(u_{k}(t)\right) d t+T \bar{h},
\end{aligned}
$$

which together with (2.6) yields

$$
u_{k}(\xi)<\frac{\left(\int_{0}^{T} \varphi_{-}(s)^{2} d s\right)^{\frac{1}{2}}}{\int_{0}^{T} \varphi_{+}(s) d s}\left(\int_{0}^{T} u_{k}(s)^{2} d s\right)^{\frac{1}{2}}+\frac{A+|\bar{h}|}{\overline{\varphi_{+}}} .
$$

It follows from $\left|u_{k}\right|_{\infty} \leq u_{k}(\xi)+T^{\frac{1}{2}}\left(\int_{0}^{T}\left|u_{k}^{\prime}(s)\right|^{2} d s\right)^{\frac{1}{2}}$ that

$$
\left|u_{k}\right|_{\infty} \leq \frac{\left(\int_{0}^{T} \varphi_{-}(s)^{2} d s\right)^{\frac{1}{2}}}{\int_{0}^{T} \varphi_{+}(s) d s}\left(\int_{0}^{T} u_{k}(s)^{2} d s\right)^{\frac{1}{2}}+\frac{A+\bar{h}}{\overline{\varphi_{+}}}+T^{\frac{1}{2}}\left(\int_{0}^{T}\left|u_{k}^{\prime}(s)\right|^{2} d s\right)^{1 / 2} .
$$

On the other hand, by multiplying equation (2.5) with $u_{k}(t)$, and integrating it over the interval $[0, T]$, we obtain

$$
\int_{0}^{T}\left|u_{k}^{\prime}(t)\right|^{2} d t=-\lambda \int_{0}^{T} g\left(u_{k}(t)\right) u_{k}(t) d t+\lambda \int_{0}^{T} \varphi(t) u_{k}^{2}(t) d t-\lambda \int_{0}^{T} h(t) u_{k}(t) d t,
$$


Lu Journal of Inequalities and Applications （2017) 2017:37

Page 6 of 13

which together with the fact of $g(x)>0$ for all $x>0$ gives

$$
\begin{aligned}
\int_{0}^{T}\left|u_{k}^{\prime}(t)\right|^{2} d t & <\lambda \int_{0}^{T} \varphi_{+}(t) u_{k}^{2}(t) d t+\lambda \int_{0}^{T} h_{-}(t) u_{k}(t) d t \\
& \leq\left|\varphi_{+}\right|_{\infty} \int_{0}^{T}\left|u_{k}(t)\right|^{2} d t+\left(\int_{0}^{T}\left|u_{k}(t)\right|^{2} d t\right)^{\frac{1}{2}}\left(\int_{0}^{T}\left|h_{-}(t)\right|^{2} d t\right)^{\frac{1}{2}}
\end{aligned}
$$

i.e.,

$$
\begin{aligned}
& \left(\int_{0}^{T}\left|u_{k}^{\prime}(t)\right|^{2} d t\right)^{1 / 2} \\
& \quad<\left|\varphi_{+}\right|_{\infty}^{1 / 2}\left(\int_{0}^{T}\left|u_{k}(t)\right|^{2} d t\right)^{\frac{1}{2}}+\left(\int_{0}^{T}\left|u_{k}(t)\right|^{2} d t\right)^{\frac{1}{4}}\left(\int_{0}^{T}\left|h_{-}(t)\right|^{2} d t\right)^{\frac{1}{4}} .
\end{aligned}
$$

By using Lemma 2, we have

$$
\left(\int_{0}^{T}\left|u_{k}(s)\right|^{2} d s\right)^{1 / 2} \leq \frac{T}{\pi}\left(\int_{0}^{T}\left|u_{k}^{\prime}(s)\right|^{2} d s\right)^{1 / 2}+\sqrt{T}\left|u_{k}(\xi)\right| .
$$

Substituting (2.7) and (2.9) into the above formula,

$$
\begin{aligned}
& \left(\int_{0}^{T}\left|u_{k}(t)\right|^{2} d t\right)^{1 / 2} \\
& <\frac{T}{\pi}\left[\left|\varphi_{+}\right|_{\infty}^{1 / 2}\left(\int_{0}^{T}\left|u_{k}(t)\right|^{2} d t\right)^{\frac{1}{2}}+\left(\int_{0}^{T}\left|u_{k}(t)\right|^{2} d t\right)^{\frac{1}{4}}\left(\int_{0}^{T}\left|h_{-}(t)\right|^{2} d t\right)^{\frac{1}{4}}\right] \\
& \quad+\frac{T^{\frac{1}{2}}\left(\int_{0}^{T} \varphi_{-}(s)^{2} d s\right)^{\frac{1}{2}}}{\int_{0}^{T} \varphi_{+}(s) d s}\left(\int_{0}^{T} u_{k}(s)^{2} d s\right)^{\frac{1}{2}}+\frac{(A+\bar{h}) T^{\frac{1}{2}}}{\overline{\varphi_{+}}} \\
& =\sigma_{1}\left(\int_{0}^{T}\left|u_{k}(t)\right|^{2} d t\right)^{\frac{1}{2}}+\frac{T}{\pi}\left(\int_{0}^{T}\left|h_{-}(t)\right|^{2} d t\right)^{\frac{1}{4}}\left(\int_{0}^{T}\left|u_{k}(t)\right|^{2} d t\right)^{\frac{1}{4}}+\frac{(A+|\bar{h}|) T^{\frac{1}{2}}}{\overline{\varphi_{+}}},
\end{aligned}
$$

where

$$
\sigma_{1}=\frac{T}{\pi}\left|\varphi_{+}\right|_{\infty}^{1 / 2}+\frac{T^{\frac{1}{2}}\left(\int_{0}^{T} \varphi_{-}(s)^{2} d s\right)^{\frac{1}{2}}}{\int_{0}^{T} \varphi_{+}(s) d s} \in(0,1)
$$

which is determined by assumption $\left[\mathrm{H}_{1}\right]$. This gives

$$
\begin{aligned}
& \left(\int_{0}^{T}\left|u_{k}(t)\right|^{2} d t\right)^{1 / 2} \\
& \quad \leq \frac{T}{\pi\left(1-\sigma_{1}\right)}\left(\int_{0}^{T}\left|h_{-}(t)\right|^{2} d t\right)^{\frac{1}{4}}\left(\int_{0}^{T}\left|u_{k}(t)\right|^{2} d t\right)^{\frac{1}{4}}+\frac{(A+|\bar{h}|) T^{\frac{1}{2}}}{\left(1-\sigma_{1}\right) \overline{\varphi_{+}}}
\end{aligned}
$$

ie.,

$$
\left(\int_{0}^{T}\left|u_{k}(t)\right|^{2} d t\right)^{\frac{1}{4}} \leq A_{0}
$$


where

$$
A_{0}=\frac{T}{\pi\left(1-\sigma_{1}\right)}\left(\int_{0}^{T}\left|h_{-}(t)\right|^{2} d t\right)^{\frac{1}{4}}+\left(\frac{(A+|\bar{h}|) T^{\frac{1}{2}}}{\left(1-\sigma_{1}\right) \overline{\varphi_{+}}}\right)^{\frac{1}{2}} .
$$

It follows from (2.9) that

$$
\left(\int_{0}^{T}\left|u_{k}^{\prime}(t)\right|^{2} d t\right)^{1 / 2}<\left|\varphi_{+}\right|_{\infty} A_{0}^{2}+A_{0}\left(\int_{0}^{T}\left|h_{-}(t)\right|^{2} d t\right)^{\frac{1}{4}} .
$$

Substituting (2.11)-(2.12) into (2.8), we have

$$
\left|u_{k}\right|_{\infty}<\frac{\left(\int_{0}^{T} \varphi_{-}(s)^{2} d s\right)^{\frac{1}{2}}}{\int_{0}^{T} \varphi_{+}(s) d s} A_{0}^{2}+\frac{A+|\bar{h}|}{\overline{\varphi_{+}}}+\left|\varphi_{+}\right|_{\infty} A_{0}^{2} T^{\frac{1}{2}}+A_{0} T^{\frac{1}{2}}\left(\int_{0}^{T}\left|h_{-}(t)\right|^{2} d t\right)^{\frac{1}{4}},
$$

which together with (2.2) yields

$$
u_{k}(t)<M_{0} \quad \text { for all } t \in[0, T]
$$

By the definition of $k_{0}$, we see from (2.3) that (2.13) contradicts (2.4). This contradiction implies that the conclusion of Lemma 3 is true.

\section{Main results}

Theorem 1 Assume that $\left[\mathrm{H}_{1}\right]-\left[\mathrm{H}_{3}\right]$ hold. Then equation (1.1) has at leat one positive Tperiodic solution.

Proof Firstly, we will show that there exist $M_{1}, M_{2}$ with $M_{1}>k^{*} M$ and $M_{2}>0$ such that each positive $T$-periodic solution $u(t)$ of equation (2.1) satisfies the inequalities

$$
u(t)<M_{1}, \quad\left|u^{\prime}(t)\right|<M_{2}, \quad \text { for all } t \in[0, T] .
$$

In fact, if $u$ is an arbitrary positive $T$-periodic solution of equation (2.1), then

$$
u^{\prime \prime}+\lambda f(u) u^{\prime}-\lambda g(u)+\lambda \varphi(t) u=\lambda h(t), \quad \lambda \in(0,1] .
$$

This implies $u \in \Omega$. So by using Lemma 3 that there is a point $t_{0} \in[0, T]$ such that

$$
u\left(t_{0}\right) \leq k^{*} M
$$

and then

$$
|u|_{\infty} \leq k^{*} M+T^{1 / 2}\left(\int_{0}^{T}\left|u^{\prime}(s)\right|^{2} d s\right)^{1 / 2} .
$$

Integrating (3.2) over the interval $[0, T]$, we have

$$
-\int_{0}^{T} g(u(t)) d t+\int_{0}^{T} \varphi(t) u(t) d t=\int_{0}^{T} h(t) d t .
$$


Lu Journal of Inequalities and Applications ( 2017) 2017:37

Page 8 of 13

Since $g(x) \rightarrow+\infty$ as $x \rightarrow 0^{+}$, we see from (3.5) that there is a point $t_{1} \in[0, T]$ such that

$$
u\left(t_{1}\right) \geq \gamma
$$

where $\gamma<k^{*} M$ is a positive constant, which is independent of $\lambda \in(0,1]$. Similar to the proof of (2.9), we have

$$
\begin{aligned}
& \left(\int_{0}^{T}\left|u^{\prime}(t)\right|^{2} d t\right)^{1 / 2} \\
& \quad<\left|\varphi_{+}\right|_{\infty}^{1 / 2}\left(\int_{0}^{T}|u(t)|^{2} d t\right)^{\frac{1}{2}}+\left(\int_{0}^{T}|u(t)|^{2} d t\right)^{\frac{1}{4}}\left(\int_{0}^{T}\left|h_{-}(t)\right|^{2} d t\right)^{\frac{1}{4}} .
\end{aligned}
$$

By using Lemma 2, we have

$$
\left(\int_{0}^{T}|u(s)|^{2} d s\right)^{1 / 2} \leq \frac{T}{\pi}\left(\int_{0}^{T}\left|u^{\prime}(s)\right|^{2} d s\right)^{1 / 2}+\sqrt{T}\left|u\left(t_{0}\right)\right|,
$$

where $t_{0}$ is determined in (3.3). Substituting (3.7) into (3.8), we have

$$
\begin{aligned}
& \left(\int_{0}^{T}|u(t)|^{2} d t\right)^{1 / 2} \\
& \quad<\frac{T}{\pi}\left[\left|\varphi_{+}\right|_{\infty}^{1 / 2}\left(\int_{0}^{T}|u(t)|^{2} d t\right)^{\frac{1}{2}}+\left(\int_{0}^{T}|u(t)|^{2} d t\right)^{\frac{1}{4}}\left(\int_{0}^{T}\left|h_{-}(t)\right|^{2} d t\right)^{\frac{1}{4}}\right] \\
& \quad+T^{\frac{1}{2}} k^{*} M \\
& =\frac{T}{\pi}\left|\varphi_{+}\right|_{\infty}^{1 / 2}\left(\int_{0}^{T}|u(t)|^{2} d t\right)^{\frac{1}{2}}+\frac{T}{\pi}\left(\int_{0}^{T}\left|h_{-}(t)\right|^{2} d t\right)^{\frac{1}{4}}\left(\int_{0}^{T}|u(t)|^{2} d t\right)^{\frac{1}{4}}+T^{\frac{1}{2}} k^{*} M,
\end{aligned}
$$

which results in

$$
\begin{aligned}
(1 & \left.-\frac{T}{\pi}\left|\varphi_{+}\right|_{\infty}^{1 / 2}\right)\left(\int_{0}^{T}|u(t)|^{2} d t\right)^{1 / 2} \\
& <\frac{T}{\pi}\left(\int_{0}^{T}\left|h_{-}(t)\right|^{2} d t\right)^{\frac{1}{4}}\left(\int_{0}^{T}|u(t)|^{2} d t\right)^{\frac{1}{4}}+T^{\frac{1}{2}} k^{*} M .
\end{aligned}
$$

Since $\frac{T}{\pi}\left|\varphi_{+}\right|_{\infty}^{1 / 2}<\sigma_{1} \in(0,1)$, it follows from (3.9) that there is a constant $\rho>0$, which is independent of $\lambda \in(0,1]$, such that

$$
\left(\int_{0}^{T}|u(t)|^{2} d t\right)^{1 / 2}<\rho
$$

and then by (3.7), we have

$$
\left(\int_{0}^{T}\left|u^{\prime}(t)\right|^{2} d t\right)^{1 / 2}<\left|\varphi_{+}\right|_{\infty}^{1 / 2} \rho+\left(\int_{0}^{T}\left|h_{-}(t)\right|^{2} d t\right)^{\frac{1}{4}} \rho^{1 / 2}
$$


It follows from (3.4) that

$$
|u|_{\infty}<k^{*} M+T^{1 / 2}\left|\varphi_{+}\right|_{\infty}^{1 / 2} \rho+(T \rho)^{1 / 2}\left(\int_{0}^{T}\left|h_{-}(t)\right|^{2} d t\right)^{\frac{1}{4}}:=M_{1}
$$

i.e.,

$$
u(t)<M_{1}, \quad \text { for all } t \in[0, T] .
$$

Now, if $u$ attains its maximum over $[0, T]$ at $t_{2} \in[0, T]$, then $u^{\prime}\left(t_{2}\right)=0$ and we deduce from (3.2) that

$$
u^{\prime}(t)=\lambda \int_{t_{2}}^{t}\left[-f(u) u^{\prime}+g(u)-\varphi(t) u+h(t)\right] d t
$$

for all $t \in\left[t_{2}, t_{2}+T\right]$. Thus, if $F^{\prime}=f$, then

$$
\begin{aligned}
& \left|u^{\prime}(t)\right| \leq \lambda\left|F(u(t))-F\left(u\left(t_{2}\right)\right)\right|+\lambda \int_{t_{2}}^{t_{2}+T} g(u(t)) d t \\
& +\lambda \int_{t_{2}}^{t_{2}+T}|\varphi(s)| u(s) d s+\lambda \int_{t_{2}}^{t_{2}+T}|h(s)| d s \\
& \leq 2 \lambda \max _{0 \leq u \leq M_{1}}|F(u)|+\lambda \int_{0}^{T} g(u(s)) d s+\lambda T \overline{|\varphi|}|u|_{\infty}+\lambda T \overline{|h|} .
\end{aligned}
$$

From (3.2), we see that

$$
\begin{aligned}
\int_{0}^{T} g(u(s)) d s & =\int_{0}^{T} \varphi(t) u(t) d t-T \bar{h} \\
& \leq T \overline{\varphi_{+}}|u|_{\infty}+T \overline{h_{-}} .
\end{aligned}
$$

It follows from (3.10) and (3.11) that

$$
\begin{aligned}
& \left|u^{\prime}(t)\right| \leq 2 \lambda\left(\max _{0 \leq u \leq M_{1}}|F(u)|+T \overline{|\varphi|}|u|_{\infty}+T \overline{|h|}\right) \\
& \quad<2 \lambda\left(\max _{0 \leq u \leq M_{1}}|F(u)|+M_{1} T \overline{|\varphi|}+T \overline{h \mid}\right) \\
& :=\lambda M_{2}, \quad t \in[0, T]
\end{aligned}
$$

and then

$$
\left|u^{\prime}(t)\right|<M_{2}, \quad \text { for all } t \in[0, T] .
$$

Equations (3.10) and (3.13) imply that (3.1) holds.

Below, we will show that there exists a constant $\gamma_{0} \in(0, \gamma)$, such that each positive $T$ periodic solution of equation (2.1) satisfies

$$
u(t)>\gamma_{0} \quad \text { for all } t \in[0, T] .
$$


Suppose that $u(t)$ is an arbitrary positive $T$-periodic solution of equation (2.1), then

$$
u^{\prime \prime}+\lambda f(u) u^{\prime}-\lambda g(u)+\lambda \varphi(t) u=\lambda h(t), \quad \lambda \in(0,1]
$$

Let $t_{1}$ be determined in (3.6). Multiplying (3.15) by $u^{\prime}(t)$ and integrating it over the interval $\left[t_{1}, t\right]$ (or $\left.\left[t, t_{1}\right]\right)$, we get

$$
\frac{\left|u^{\prime}(t)\right|^{2}}{2}-\frac{\left|u^{\prime}\left(t_{1}\right)\right|^{2}}{2}+\lambda \int_{t_{1}}^{t} f(u)\left(u^{\prime}\right)^{2} d t=\lambda \int_{t_{1}}^{t} g(u) u^{\prime} d t-\lambda \int_{t_{1}}^{t} \varphi(t) u u^{\prime} d t+\lambda \int_{t_{1}}^{t} h(t) u^{\prime} d t
$$

which yields the estimate

$$
\begin{aligned}
\lambda\left|\int_{u(t)}^{u\left(t_{1}\right)} g(s) d s\right| \leq & \frac{\left|u^{\prime}(t)\right|^{2}}{2}+\frac{\left|u^{\prime}\left(t_{1}\right)\right|^{2}}{2}+\lambda \int_{0}^{T}|f(u)|\left(u^{\prime}\right)^{2} d t \\
& +\lambda \int_{0}^{T}\left|\varphi(t) u u^{\prime}\right| d t+\lambda \int_{0}^{T}\left|h(t) u^{\prime}\right| d t .
\end{aligned}
$$

From (3.10) and (3.12), we get

$$
\lambda\left|\int_{u(t)}^{u\left(t_{1}\right)} g(s) d s\right| \leq \lambda M_{2}^{2}+\lambda \max _{0 \leq u \leq M_{1}}|f(u)| T M_{2}^{2}+\lambda M_{1} M_{2} T \overline{|\varphi|}+\lambda M_{2} T \overline{|h|},
$$

which gives

$$
\left|\int_{u(t)}^{u\left(t_{1}\right)} g(s) d s\right| \leq M_{3}, \quad \text { for all } t \in\left[t_{1}, t_{1}+T\right]
$$

with

$$
M_{3}=M_{2}^{2}+\max _{0 \leq u \leq M_{1}}|f(u)| T M_{2}^{2}+M_{1} M_{2} T \overline{|\varphi|}+M_{2} T \overline{|h|} .
$$

From $\left[\mathrm{H}_{3}\right]$ there exists $\gamma_{0} \in(0, \gamma)$ such that

$$
\int_{\eta}^{\gamma} g(u) d u>M_{3}, \quad \text { for all } \eta \in\left(0, \gamma_{0}\right]
$$

Therefore, if there is a $t^{*} \in\left[t_{1}, t_{1}+T\right]$ such that $u\left(t^{*}\right) \leq \gamma_{0}$, then from (3.17) we get

$$
\int_{u\left(t^{*}\right)}^{\gamma} g(s) d s>M_{3}
$$

which contradicts (3.16). This contradiction gives that $u(t)>\gamma_{0}$ for all $t \in[0, T]$. So (3.14) holds. Let $m_{0}=\min \left\{D_{1}, \gamma_{0}\right\}$ and $m_{1} \in\left(M_{1}+D_{2},+\infty\right)$ be two constants, then from (3.1) and (3.14), we see that each possible positive $T$-periodic solution $u$ to equation (2.1) satisfies

$$
m_{0}<u(t)<m_{1}, \quad\left|u^{\prime}(t)\right|<M_{2} .
$$

This implies that condition 1 and condition 2 of Lemma 1 are satisfied. Also, we can deduce from Remark 1 that

$$
g(c)-\bar{\varphi} c+\bar{h}>0, \quad \text { for } c \in\left(0, m_{0}\right]
$$


and

$$
g(c)-\bar{\varphi} c+\bar{h}<0, \quad \text { for } c \in\left[m_{1},+\infty\right)
$$

which results in

$$
\left(g\left(m_{0}\right)-\bar{\varphi} m_{0}+\bar{h}\right)\left(g\left(m_{1}\right)-\bar{\varphi} m_{1}+\bar{h}\right)<0 .
$$

So condition 3 of Lemma 1 holds. By using Lemma 1, we see that equation (1.1) has at least one positive $T$-periodic solution. The proof is complete.

Let us consider the equation

$$
x^{\prime \prime}+f(x) x^{\prime}-\frac{1}{x^{\gamma}}+\varphi(t) x=h(t)
$$

where $f:[0,+\infty) \rightarrow R$ is an arbitrary continuous function, $\varphi, h: R \rightarrow R$ are $T$-periodic functions with $h \in L^{1}([0, T], R)$ and $\varphi \in C([0, T], R)$, and the sign of the function $\varphi$ is allowed to change for $t \in[0, T], \gamma \geq 1$ is a constant. Corresponding to equation (1.1), $g(x)=\frac{1}{x^{\gamma}}$. For this case, $g(x) \rightarrow+\infty$ as $x \rightarrow 0^{+}$, and assumptions $\left[\mathrm{H}_{2}\right]-\left[\mathrm{H}_{3}\right]$ are satisfied. Thus, by using Theorem 1 , we have the following results.

Corollary 1 Assume that the function $\varphi(t)$ satisfies the following conditions:

$$
\int_{0}^{T} \varphi_{+}(s) d s>0, \quad \sigma:=\frac{\int_{0}^{T} \varphi_{-}(s) d s}{\int_{0}^{T} \varphi_{+}(s) d s} \in[0,1)
$$

and

$$
\sigma_{1}:=\frac{T}{\pi}\left|\varphi_{+}\right|_{\infty}^{1 / 2}+\frac{T^{\frac{1}{2}}\left(\int_{0}^{T} \varphi_{-}(s)^{2} d s\right)^{\frac{1}{2}}}{\int_{0}^{T} \varphi_{+}(s) d s} \in(0,1) .
$$

Then, equation (3.18) possesses at least one positive T-periodic solution.

Remark 2 Corresponding to equation (1.4) and equation (1.5), the function $g(t, x)$ associated to equation (3.18) can be regarded as

$$
g(t, u)=-\frac{1}{u^{\gamma}}+\varphi(t) u-h(t), \quad(t, u) \in[0, T] \times(0,+\infty) .
$$

For the case of $\varphi(t) \geq 0$ for all $t \in[0, T]$, we see that if $x$ is a positive $T$-periodic continuous function satisfying $\int_{0}^{T} g(t, x(t)) d t=0$, then

$$
\int_{0}^{T} \frac{1}{x^{\gamma}(t)} d t=\int_{0}^{T} \varphi(t) x(t) d t-\int_{0}^{T} h(t) d t
$$

By applying the integral mean value theorem to the term $\int_{0}^{T} \varphi(t) x(t) d t$ in equation (3.20), one can easily verify that $g(t, u)$ determined in (3.19) satisfies the balance condition $\left(\mathrm{h}_{1}\right)$. However, if the sign of the function $\varphi(t)$ is changeable for $t \in[0, T]$, then it is unclear from 
(3.20) whether the balance condition $\left(\mathrm{h}_{1}\right)$ is satisfied. For this case, the main results of [18, 19] cannot be applied to equation (3.18).

Corollary 2 Assume that the function $\varphi(t)$ satisfies $\varphi(t) \geq 0$ for all $t \in[0, T]$ with $\int_{0}^{T} \varphi(s) d s>0$, and

$$
|\varphi|_{\infty}<\left(\frac{\pi}{T}\right)^{2}
$$

Then, equation (3.18) possesses at least one positive T-periodic solution.

Example 1 Consider the following equation:

$$
x^{\prime \prime}(t)+f(x(t)) x^{\prime}(t)-\frac{1}{x^{2}(t)}+a(1+2 \sin 2 t) x(t)=\cos 2 t,
$$

where $f$ is an arbitrary continuous function, $a \in(0,+\infty)$ is a constant. Corresponding to equation (3.18), we have $\gamma=2, \varphi(t)=a(1+2 \sin 2 t)$ and $h(t)=\cos 2 t, T=\pi$. By simply calculating, we can verify that

$$
\begin{aligned}
& \int_{0}^{T} \varphi_{+}(t) d t=\left(\frac{2 \pi}{3}+\frac{3}{2}\right) a, \quad \int_{0}^{T} \varphi_{-}(t) d t=\left(\frac{3}{2}-\frac{\pi}{3}\right) a \\
& \int_{0}^{T}\left(\varphi_{-}(t)\right)^{2} d t=\frac{3 \pi a}{2}
\end{aligned}
$$

and then

$$
\sigma:=\frac{\int_{0}^{T} \varphi_{-}(s) d s}{\int_{0}^{T} \varphi_{+}(s) d s}=\frac{9-2 \pi}{4 \pi+9} \in(0,1)
$$

and

$$
\sigma_{1}:=\frac{T}{\pi}\left|\varphi_{+}\right|_{\infty}^{1 / 2}+\frac{T^{\frac{1}{2}}\left(\int_{0}^{T} \varphi_{-}(s)^{2} d s\right)^{\frac{1}{2}}}{\int_{0}^{T} \varphi_{+}(s) d s}=\sqrt{3 a}+\frac{3 \pi \sqrt{6}}{4 \pi+9} .
$$

Thus, if $0<a<\frac{1}{3}\left(\frac{4 \pi+9-3 \pi \sqrt{6}}{4 \pi+9}\right)^{2}$, then $\sigma_{1} \in(0,1)$. By using Corollary 1 , we see that equation (3.21) has at least one positive $\pi$-periodic solution.

Remark 3 Since the sign of $\varphi(t)=1+2 \sin t$ is changed for $t \in[0, T]$, whether the right inequality of (1.6) in the balance condition $\left(h_{1}\right)$ is satisfied remains unclear. So the conclusion of the example cannot be obtained by using the main results in $[18,19]$.

The author declares to have no competing interests. 


\section{References}

1. Forbat, N, Huaux, A: Détermination approachée et stabilité locale de la solution périodique d'une equation différentielle non linéaire. Mém. Public. Soc. Sci. Arts Letters Hainaut. 76, 3-13 (1962)

2. Huaux, A: Sur L'existence d'une solution périodique de l'équation différentielle non linéaire $x^{\prime \prime}+0.2 x^{\prime}+\frac{x}{1-x}=\cos \omega t$. Bull. Cl. Sci., Acad. R. Belg. 48, 494-504 (1962)

3. Lei, J, Zhang, MR: Twist property of periodic motion of an atom near a charged wire. Lett. Math. Phys. 60(1), 9-17 (2002)

4. Adachi, S: Non-collision periodic solutions of prescribed energy problem for a class of singular Hamiltonian systems. Topol. Methods Nonlinear Anal. 25, 275-296 (2005)

5. Hakl, R, Torres, PJ: On periodic solutions of second-order differential equations with attractive-repulsive singularities. J. Differ. Equ. 248, 111-126 (2010)

6. Jebelean, $\mathrm{P}$, Mawhin, J: Periodic solutions of singular nonlinear perturbations of the ordinary $p$-Laplacian. Adv. Nonlinear Stud. 2, 299-312 (2002)

7. Tanaka, K: A note on generalized solutions of singular Hamiltonian systems. Proc. Am. Math. Soc. 122, 275-284 (1994)

8. Terracini, S: Remarks on periodic orbits of dynamical systems with repulsive singularities. J. Funct. Anal. 111, 213-238 (1993)

9. Solimini, S: On forced dynamical systems with a singularity of repulsive type. Nonlinear Anal. 14, 489-500 (1990)

10. Gaeta, S, Manásevich, R: Existence of a pair of periodic solutions of an ode generalizing a problem in nonlinear elasticity via variational methods. J. Math. Anal. Appl. 123, 257-271 (1988)

11. Fonda, A: Periodic solutions for a conservative system of differential equations with a singularity of repulsive type. Nonlinear Anal. 24, 667-676 (1995)

12. Fonda, A, Manásevich, R, Zanolin, F: Subharmonic solutions for some second-order differential equations with singularities. SIAM J. Math. Anal. 24, 1294-1311 (1993)

13. Jiang, D, Chu, J, Zhang, M: Multiplicity of positive periodic solutions to superlinear repulsive singular equations. J. Differ. Equ. 211, 282-302 (2005)

14. Chu, J, Torres, PJ, Zhang, M: Periodic solutions of second order non-autonomous singular dynamical systems. J. Differ. Equ. 239, 196-212 (2007)

15. Li, X, Zhang, Z: Periodic solutions for second order differential equations with a singular nonlinearity. Nonlinear Anal. 69, 3866-3876 (2008)

16. Lazer, AC, Solimini, S: On periodic solutions of nonlinear differential equations with singularities. Proc. Am. Math. Soc. 99, 109-114 (1987)

17. Martins, R: Existence of periodic solutions for second-order differential equations with singularities and the strong force condition. J. Math. Anal. Appl. 317, 1-13 (2006)

18. Zhang, M: Periodic solutions of Liénard equations with singular forces of repulsive type. J. Math. Anal. Appl. 203 254-269 (1996)

19. Wang, Z: Periodic solutions of Liénard equations with a singularity and a deviating argument. Nonlinear Anal., Real World Appl. 16, 227-234 (2014)

20. Hakl, R, Torres, PJ, Zamora, M: Periodic solutions to singular second order differential equations: the repulsive case. Topol. Methods Nonlinear Anal. 39(2), 199-220 (2012)

21. Lu, S, Zhong, T, Chen, L: Periodic solutions for $p$-Laplacian Rayleigh equations with singularities. Bound. Value Probl. 2016, 96 (2016). doi:10.1186/s13661-016-0605-8

22. Lu, S, Zhong, T, Gao, Y: Periodic solutions of $p$-Laplacian equations with singularities. Adv. Differ. Equ. 2016, 146 (2016). doi:10.1186/s13662-016-0875-6

23. Manásevich, R, Mawhin, J: Periodic solutions for nonlinear systems with $p$-Laplacian-like operators. J. Differ. Equ. 145 367-393 (1998)

\section{Submit your manuscript to a SpringerOpen ${ }^{\ominus}$ journal and benefit from:}

- Convenient online submission

- Rigorous peer review

- Immediate publication on acceptance

- Open access: articles freely available online

- High visibility within the field

- Retaining the copyright to your article 